\title{
EXPERIENCE OF SEXUAL HARASSMENT IN PUBLIC TRANSPORT AMONG FEMALE HEALTH SCIENCE STUDENTS: A CROSS SECTIONAL STUDY OF KATHMANDU, NEPAL.
}

Mishra D ${ }^{1}$ Lamichhane $\mathrm{J}^{2}$

1,2 Department of Public health, Manmohan Memorial Institute of Health Sciences, Soaltee mode, Kathmandu

Corresponding Author:

Durga Mishra, Associate Professor, Department of Public Health, Manmohan Memorial Institute of Health Sciences, Soaltee mode, Kathmandu, Email: durgamk07@ gmail.com

\section{ABSTRACT}

Background: Sexual harassment on public transport is an everyday occurrence for millions of girls and women around the globe. With the skyrocketing population of Kathmandu valley public transport has been facing enormous pressure. The major victims of these harassments happens to be college going girls and working women as they tend to travel more in public transports. This study sought to determine the prevalence and factors responsible for sexual harassment in public transport among female health science students.

Methods: A descriptive cross-sectional study was carried out among 396 female health science students studying in Manmohan Memorial Institute of Health Sciences using self-administered structured questionnaire. Participants were selected through stratified random sampling method.

Results: The prevalence of sexual harassment among female health science students was found to be $79.6 \%$. Physical harassment was the most prominent type of harassment $(67.1 \%)$ followed by verbal $(61.2 \%)$ and non verbal $34.6 \%$. After the experience of sexual harassment, $44.6 \%$ scolded the harasser, $29.1 \%$ kept silent, $17.3 \%$ dropped at nearest bus station whereas remaining $9 \%$ reacted in other different ways. Overcrowding was considered as main reason for sexual harassment by $69.2 \%$ of the participants. $36.8 \%$ of female students didn't use any precautionary methods whereas $32.6 \%$ avoided going out alone at night.

Conclusion: The study reveals that the prevalence of sexual harassment is significantly high. With increasing population and limited vehicles people are left with no option rather than travelling in the overcrowded vehicles where the chances of experiencing various sorts of sexual harassments are very high. In order to address this emerging issue, prompt and appropriate intervention should be taken by government, public and especially the status of women must be raised in society.

Key words: sexual harassment, health science student, perpetrator

\section{INTRODUCTION}

Sexual harassment against women is an incidence of violation of personal space of women by individual or groups of men where they do uninvited sexual advances, unwelcomed gestures, comments, insults, slurs and other obscenities at women in public places. ${ }^{1}$ It can exist as any 
form of sexual contact or activity ranging from verbal abuse to physical assault. ${ }^{2}$ The following are the behaviors which could be considered as sexual harassment when they are unwelcomed:

Verbal: Whistling or making cat calls at someone; making sexual comments about a person's clothing or body; telling sexual jokes or stories ${ }^{2}$

Non-verbal: Paying unwanted attention to someone (i.e., staring, following, blocking a person's path) displaying sexually suggestive visuals; making facial expressions such as winking, throwing kisses, or licking ${ }^{2}$

Physical: Hanging around, standing close, or brushing up against a person; touching a person's clothing, hair, or body touching or rubbing oneself sexually around another person; hugging, kissing, patting or stroking. ${ }^{2}$

With the male dominant society and traditional mindset, even today, women feel embarrassed to make police complain about the harassment they experience and only a few dare due to fear that the shame of the act would fall upon them, not the perpetrators. This persistent violence affects the survivors in many ways particularly manifestation of physical, mental and social disorders and consequently, it reduces their ability to participate in educational and professional activities and in public life. ${ }^{5,6}$

Though being a very contemporary issue, very few studies on sexual harassment in public transports in Nepal have been done till date. This study therefore is out small attempt to find out the prevalence and the responsible factors for everyday occurrence of sexual harassment in public transport.

\section{MATERIALS AND METHODS}

\section{Study Area}

This study was conducted in Kathmandu. Kathmandu district is one of the three districts located in Kathmandu Valley, which itself is located in the hills of Bagmati Zone, Central Development Region, Nepal. The total population of the district is 1,744,240 out of which 913,001 are male and 831,239 female in 436,355 households. Average family size is 4.0 in 2011 (CBS, 2011).

\section{Study Design}

A descriptive cross sectional study was carried to access prevalence and responsible factors of sexual harassment among female heath science students studying in Manmohan Memorial Institute of Health Sciences.

\section{Sampling Technique}

Stratified random sampling method was adopted for the selection of students. The students were first divided into various strata according to their faculty from where they were chosen randomly.

\section{Study Population}

This study was conducted among female health science students studying in Manmohan Memorial Institute of Health Sciences.

\section{Sample Size Estimation}


The sample size was determined by single population proportion formula. Based on the study conducted among women travelling in public transport in Chennai city, India in 2008, the sample size for this study $63.0 \%$ was used. Therefore at $95 \%$ confidence level and $5 \%$ margin of error along with the addition of $10 \%$ non response rate, the sample size was calculated to be 396 .

\section{Data Collection Tools and Techniques}

Data was collected from the participant with the help of self administered structured questionnaire. Due to unavailability of any standard questionnaire to measure prevalence of sexual harassment in public transport, we developed a set of questionnaire after adequate literature review. The inclusion criteria were female health science students who were studying at Manmohan Memorial Institute of Health Sciences at that time.

\section{Ethical Considerations}

Ethical approval was obtained from Institutional Review Committee of Manmohan Memorial Institute of Health Sciences (MMIHS). Written informed consent was obtained from each respondent with detail explanation of the purpose of the study to ensure their right to information. Confidentiality of the respondent was maintained with an exemption to participate in the study or refuse to answer the question which they felt awkward with.

\section{RESULTS}

A total of 396 female health science students studying in Manmohan Memorial Institute of Health Sciences were studied to determine the prevalence and factors responsible for sexual harassment in public transport.

\section{Socio-demographic Information}

Mean age of the respondents participated in this study was 19.95 years. Majority of the participants i.e. $52.3 \%$ were aged 20 or more. When sorting on the basis of ethnicity majority belonged to Brahmin / Chhetri (57.1\%) followed by Janajati (34.6\%), Madhesi (3.0\%),Dalit $(1.0 \%)$, Muslim $(0.5 \%)$ and others being $3.8 \%$. Majority $60.4 \%$ of the participants were studying in Bachelor level while the remaining 39.6 were in Proficiency Certificate level. Nearly three quarter of participants $(72.5 \%)$ had origin outside the valley. Majority $(93.1 \%)$ had monthly income of NRs 60,000 or less. While exploring the marital status it was found that only $5.57 \%$ were married.(Table 1). The relation of these socio-demographic characteristics with the experience of sexual harassment has been shown further in Table 5.

Table 1. Socio-demographic characteristics

\begin{tabular}{lll}
\hline Characteristics & Frequency & Percentage $(\%)$ \\
\hline Age $(\mathbf{n}=\mathbf{3 9 6})$ & & \\
$<20$ years & 189 & 47.7 \\
$\geq 20$ years & 207 & 52.3 \\
\end{tabular}


Ethnicity $(n=396)$

Brahmin/Chhetri

226

57.1

Janajati

137

34.6

Madhesi

12

3

Dalit

4

1

Muslim

2

0.5

Others

Education level $(n=396)$

PCL

Bachelor

60.4

Income of family $(n=396)$

$\leq 60,000$

93.1

$>60,000$

6.9

Origin of family $(n=396)$

Inside valley

Outside valley

Marital status (n=396)

Married

Unmarried

374

94.83

\section{Indicators associated with experience of sexual harassment}

Among the total participants of the study, 91.7\% used public transport in regular basis while the remaining used their own private vehicles. The most used type of vehicle was found to be bus $(59 \%)$ followed by micro-buses $(39.7 \%)$ while remaining used other means like tempo and blue gas van. Larger fraction of the sample population $(92.8 \%)$ spent two hours or less in public transport on a daily basis. 
363 participants who used public transport on regular basis were asked if they had experienced sexual harassment in public transport, among which $79.6 \%$ had experienced sexual harassment which is significantly very high. (Table 2)

Table 2. Indicators associated with experience of sexual harassment

\begin{tabular}{|l|l|l|}
\hline Indicators & Frequency & Percentage $(\%)$ \\
\hline
\end{tabular}

Use of public vehicle in regular basis $(n=396)$

Yes

363

No

Type of vehicle used $(n=363)$

Bus

Micro-bus

Others

5

Average hours spent in vehicle $(n=363)$

$\leq 2$ hours

$>2$ hours

108

Ever been sexually harassed in public vehicle $(n=363)$

Yes

289

79.6

No

74

20

\section{Indicators associated with occurrence of sexual harassment}

When inquired about the experience in last 6 months $17.3 \%$ had experienced harassment four times or more where as $82.7 \%$ experienced less than 4 times. Majority of participants experienced physical harassment $(67.1 \%)$ followed by verbal $(61.2 \%)$ and non verbal (34.6\%).

Moving on to perpetrators of sexual harassment, the lion's share was held by other fellow passengers travelling in the same transport which was $92.4 \%$. Remaining $7.6 \%$ perpetrators were found to be bus drivers and conductors.

More than half of the perpetrators $(55.7 \%)$ belonged to age group 25-45 years, followed by less than 25 years $(35.6 \%)$ and more than 45 years $(8.7 \%)$. 
Harassments were more common during the day time $(87.2 \%)$ as compared to night $(60.9 \%)$. Majority experienced harassment while wearing college uniform (69.9\%), followed by jeans/ t-shirt (55.9\%), kurtha/tops (15.7\%) and sari as well as skirt 5.2\%. Exploring the reactions of the victims, larger fraction scolded the harasser (44.6\%), 29.1\% kept silent, $17.3 \%$ dropped at nearest bus station and $9 \%$ adopted other methods. When asked about how they felt after sexual harassment, majority of them felt angry (79.5\%) followed by humiliated (47.9\%), scared (45.5\%), helpless $(38.5 \%)$, traumatized (11.5\%), loss of interest in study (7.6\%). $2.1 \%$ were not affected by it at and more surprisingly $0.3 \%$ enjoyed it.(Table 3 ).

Table 3. Indicators associated with occurrence of sexual harassment

\begin{tabular}{lll}
\hline Indicators & Frequency & Percentage $(\%)$ \\
\hline
\end{tabular}

Experience of sexual harassment in past 6 months $(n=289)$

$\begin{array}{lll}<4 \text { times } & 239 & 82.7 \\ \geq 4 \text { times } & 50 & 17.3\end{array}$

Types of sexual harassment faced* $(n=289)$

Verbal

Non verbal

Physical

Harassed by whom $(n=289)$

Other fellow passengers

92.4

Bus operators (Driver/conductor)

Estimated age of the harasser $(n=289)$

Younger age group $(<25$ years $)$

Middle age group (25-45 years)

Older age group ( $>45$ years)

Time of harassment* $(n=289)$

Day (morning/afternoon) 252

Night (evening/night) 
Clothes worn when harassed $*(n=289)$

College uniform

Kurtha/tops

Saree

Jeans/Tshirt

Skirt

Sexual harassment makes you feel* $(n=289)$

Humiliated

Angry

I enjoy it

2

0.7

Reaction when harassed $(n=289)$

Scold the harasser

Keep silent

Counterattack/beat harasser

12

Drop at nearest bus station

50

17.3

Ask others for help

9

3.1

Call relatives

1

0.3

Cry

4

1.4

Note: * mark represents multiple responses 


\section{Indicators associated with police complain, reasons and precautionary methods of sexual harassment}

Only $2.1 \%$ of participants who had experienced harassment complained to police while other $97.9 \%$ didn't. Among the 6 people who complained only one was sure that perpetrator was punished while others didn't know. The major reason for not complaining was seen as being scared $(32.2 \%)$ followed by lack of confidence (24\%). It was found that $20.1 \%$ of them didn't complain because they didn't want others to know they were harassed and $14.1 \%$ even thought that it was common for girls to be harassed. For $9.5 \%$ of them it was not an important matter to complain.

$60.7 \%$ replied crowded vehicle as a major reason for sexual harassment. When asked about other reasons $54.4 \%$ felt harassers were not punished by police anyways, $50.7 \%$ said cultural dominance of men over women, $48.5 \%$ felt it was due to weakness of women, $46.9 \%$ said that men find it fun, $36.2 \%$ thought because it was mainly for men, 33\% said due to sexual frustration of men and $25.5 \%$ of the total females thought it was provoking dress which invited harassment.

Talking about precautionary methods majority didn't used any of the methods $(36.8 \%)$ whereas $32.6 \%$ preferred avoiding going out at night, $21.6 \%$ preferred to stop wearing clothes that might seem provocative whereas $18.8 \%$ carried self defensive items such as safety pin and pepper spray.(Table 4).

Table 4. Indicators associated with police complain, reasons and precautionary methods of sexual harassment

\begin{tabular}{lll}
\hline Indicators & Frequency & Percentage $\%$ \\
\hline
\end{tabular}

Complain to police after harassment $(n=289)$

Yes

6

No

Punishment to harasser by police $(n=6)$

Yes

No

0

0.0

Don't know

Reason for not complaining $(\mathbf{n}=289)$

Scared 
harassed

Lack of confidence $\quad 68$

24.0

Don't think it is an important matter

27

9.5

It is common for girls to be harassed

40

14.1

Crowded vehicle as main reason for sexual harassment $(n=396)$

Yes

241

60.7

No

155

39.3

Other reasons for sexual harassment* $(n=396)$

They think it is manly

135

36.2

They think it is fun

175

46.9

Provoking dress

95

25.5

Weakness of women

181

48.5

Sexual frustration of men

123

33.0

Harassers are not punished by police

203

54.4

Cultural dominance of men over women

189

50.7

Precautionary method used to avoid sexual harassment* $(n=396)$

Avoid going out alone

64

16.5

Avoid using certain vehicle type

Having someone to accompany while 72

18.5 travelling

Avoid going out at night

Avoid wearing some clothes which may

84

21.6 seem provocative

Carry items such as safety pin, pepper 73

18.8 spray 
I don't use any of these methods

143

36.8

Note: * mark represents multiple responses

Bivariate analysis of various independent variables and experience of sexual harassment

Bivariate analysis results shows that there is significant relation between overcrowding of vehicle $(p=0.000, p \leq 0.05)$, type of vehicle used $(p=0.033, p \leq 0.05)$ and average hours spent in vehicle $(\mathrm{p}=0.033, \mathrm{p} \leq 0.05)$ with the experience of sexual harassment.

Table 5. Relation between sexual harassment and independent variables.

\begin{tabular}{lllll}
\hline Factors & Experience of sexual harassment & OR & $95 \%$ CI & P value
\end{tabular}

Experienced Not experienced

$\mathbf{n}(\mathbf{2 8 9}) \quad \mathbf{n}(\mathbf{7 4})$

Age

$<20$ years

142

35

$1.076 \quad 0.646-1.795$

0.778

$\geq 20$ years

147

39

1

Marital status

Married

18

1

4.849

0.637-36.925

0.054

Unmarried

271

73

1

Overcrowding of vehicle

Yes

178

74

0.706

0.652-0.765

$0.000 * *$

No

111

0

1

Type of vehicle used

$\begin{array}{llllll}\text { Bus } & 162 & 52 & 0.540 & 0.311-0.935 & 0.0024 * * \\ \text { Others } & 127 & 22 & 1 & \end{array}$

Average hours spent in public transport

$\leq 2$ hours

264

73

$0.145 \quad 0.019-1.086$

$0.011 * *$ 
$>2$ hours

\section{Origin of family}

Inside valley 77

212

21

53

Outside valley

Education level

PCL

120

30

44

Bachelor

169
1

$0.917 \quad 0.519-1.619 \quad 0.765$

1

$1.041 \quad 0.619-1.751 \quad 0.878$

1

Note: *p<0.0001**Value of Fisher Exact's test as expected counts are less than 5

\section{DISCUSSION}

This study revealed that $79.6 \%$ of female health science students had experienced sexual harassment. Though no any research have been conducted specifically upon the students in Nepal, a research conducted by Chockalingam K and Vijaya A conducted in India revealed the prevalence as $63.0 \%{ }^{2}$ Though this study showed higher prevalence than this study it was a way too less than the prevalence found by Neupane G and Lind MC in their research Violence against women on public transport in Nepal: sexual harassment and the spatial expression of male privilege which was found to be $97 \% .^{15}$

The age group with highest prevalence of sexual harassment was found to be $\geq 20-30$ years similar to the age group revealed by The World Bank Report. However in this study people in that very age group experienced $52.3 \%$ harassment while in later $91 \%$ experienced it. ${ }^{3}$

The acts of harassments were found to be much higher in this study during both day and night time as compared to that with the study conducted in Kathmandu valley by The World Bank. The experience during day and night time were found to be $87.2 \%$ and $60.9 \%$ respectively while in the later, it was found to be $41 \%$ and $36 \%$ respectively. ${ }^{3}$

Similarly overcrowding was thought as a main reason for sexual harassment by $69.19 \%$ of the participants of this study whereas $80 \%$ reported it as main reason in the World Bank Report. ${ }^{3}$

92.4\% found fellow passengers as main perpetrators involved in harassment which is quite high than the research conducted by Lucas et al for Action Aid, where it was only $42 \%{ }^{6}$ Similarly the same study revealed that $11 \%$ of the victims reported the case to police which is higher as compared to this study. Here only $2.07 \%$ of the participants dared to make a police complain.

Only $9.5 \%$ of the victims didn't complain to police because they thought the case of harassment was not important enough in this study whereas in the similar study by Chockalingam $\mathrm{K}$ and Vijaya A, 76\% of the victims didn't complain due to the same reason. ${ }^{4}$

While exploring the reason for sexual harassment, this study revealed no good provision of punishment for perpetrators as main factor which was as high as $54.4 \%$ whereas according to 
Neupane $\mathrm{G}$ and Lind MC the main reason was found to be male dominated society which was $46.29 \%$. ${ }^{7}$ However male dominated societies was one of the prominent reasons in this study too being $50.7 \%$. Also in the same research weakness of women was quoted as $41.71 \%$ which is quite less than this research where it is $48.5 \%$. Seemingly provoking outfit was considered as a reason for harassment by $25.5 \%$ of participants which is quite high as compared to this study by Neupane G and Lina MC where it is only $6.86 \%{ }^{7}$

Exploring about the reaction after being harassed $29.1 \%$ of the participants preferred to keep silent here which is quite low as compared to study report by Lucas S, Travers K, Gauvin SM, Talvot Vin Women and the City III where $73 \%$ of the participants preferred to keep silent. ${ }^{12}$

Similarly $37.9 \%$ of the participants helped the one being harassed in our study which is quite higher than in the one by Chockalingam $\mathrm{K}$ and Vijaya A, where it was only found to be $9 \%{ }^{2}$

\section{CONCLUSION}

On the basis of this study it was found that sexual harassment in public transport has really been a burning issue these days. Physical harassment was the most prominent type of sexual harassment followed by verbal and non verbal. Majority $79.6 \%$ have experienced sexual harassment in public transport. After being harassed highest percentage of participants chose to scold the harassed followed by keeping silent and dropping at nearest bus station. Overcrowding was considered as main reason for harassment by $60.7 \%$ of participants along with no punishment for harassers by police by $54.4 \%$ and cultural dominance of men by $36.7 \%$. Highest percentage of participants i.e. 35.8\% didn't use any precautionary methods whereas 32.6\% avoided going out at night and $18.8 \%$ carried items such as safety pin and pepper spray for precaution.

\section{ACKNOWLEDGEMENT}

We would like to express our gratitude to department of Public Health, Manmohan Memorial Institute of Health Sciences for giving this opportunity to conduct this study.

We are grateful to whole team of the college for their encouragement and direction throughout the process. We are thankful Assistant Campus Chief, Prof. Dr. Sujan Babu Marahattha for providing his expertise.

We are equally indebted and express our gratitude towards Asst. Prof. Lekha Bahadur Gurung, Lecturer Jyoti Chandra Ojha, Lecturer Jay Prasad Singh, and Mrs. Sunita Dhakal along with all the faculty and colleagues for their help and encouragement.

Last but not the least we would like to thank students of MMIHS for their crucial participation in this research.

\section{REFERENCE}

1. Thapa C, Rana A. Sexual harassment in public places in Kathmandu Valley. Kathmandu: SAATHI; 1994. P4 
2. Chockalingam K, Vijaya A. Sexual Harassment of Women in Public Transport in Chennai City- A Victimology Perspective. The Indian Journal of Criminology and Criminalistics. 2008; XXIX (3): 167-168.

3. Paudel R. Understanding Masculinities in Public Transport. Kathmandu: 2011;;SANAM Fellowship Program: February- November 2011: 5-6.

4. Khatri K. Stop Sexual Harassment Blog Correspondent. Nepal [Internet]. Available at https://www.facebook.com/bsn.against.harassment/posts/1497317510554322

5. Jagori and UN Women, Safe Cities Free of Violence against Women and Girls initiative. Report of the Baseline Survey Delhi. 2010 Delhi: New Concept Information Center. 2010; 16-20, 25-33

6. Social Policy and Development Center (SDPC), Rapid Assessment of Sexual Harassment in Public Transport and Connected Spaces in Karachi. 2014; 33-36.

7. Taylor A. Women and the City, Examining the Gender Impact of Violence and Urbanization, A Comparative Study of Brazil, Cambodia, Ethiopia, Liberia and Nepal. Action Aid International; 2011; 49-52

8. Natarajan M. Rapid assessment of "eve teasing" (sexual harassment) of young women during the commute to college In India. Crime Science. 2016; S:6: P9

9. Madan M, Nalla MK. Sexual Harassment in Public Spaces: Examining Gender Differences in Perceived Seriousness and Victimization. International Criminal Justice Review. 2016;1-18, Georgia State University: P18

10. Wilkinson S. Meet the Heroic Campaigners Making Cities Safe for Women. Global Street Harassment -Making Street Safer: Action Aid [Internet]Available at http://www.refinery29.uk/women-safer-cities

11. Harrison J. Gender segregation on public transport in South Asia: A critical evaluation of approaches for addressing harassment against women. University of London. 2012; 1-8

12. Lucas S, Travers K, Gauvin SM, Talvot V. Women and the City III, A summary on baseline data on women's experience of violence in seven countries. Action Aid International. 2016; 3: 1-26

13. Overseas Security Advisory Council (OSAC) Timor-Leste. Timor-Leste 2016 Crime and Safety Report. Research and Information Support Center (RISC); 2016.

14. Malla SP, "Violence against women: Good practices in combating and eliminating violence against women" Expert Group Meeting. : UN Division for the Advancement of Women. Austria. 2005; 1-10

15. Neupane G and Lind MC, Violence against women on public transport in Nepal: sexual harassment and the spatial expression of male privilege. International Journal of Comparative and Applied Criminal Justice. 2013; 7-16

16. The World Bank Group and Australian Aid. Gender and Public Transport. Kathmandu, Nepal. 2013; 8-18 